\title{
Pancreatic involvement in small cell lung cancer
}

\author{
Ugur Gonlugur ${ }^{1}$, Arzu Mirici1 ${ }^{1}$, Muammer Karaayvaz² $^{2}$ \\ 1 Department of Chest Diseases, School of Medicine, Canakkale Onsekiz Mart University, 17100 Canakkale, Turkey \\ 2 Department of General Surgery, School of Medicine, Canakkale Onsekiz Mart University, 17100 Canakkale, Turkey
}

Radiol Oncol 2014; 48(1): 11-19.

Received 5 October 2012

Accepted 2 December 2012

Correspondence to: Ugur Gonlugur, Canakkale Onsekiz Mart Universitesi, Tip Fakultesi, Gogus Hastaliklari AD. 17100, Turkey; Fax: +90 286 2183738; E-mail: gonlugur@gmail.com

Disclosure: No potential conflicts of interest were disclosed.

Background. Few data are available concerning incidence, clinical picture, and prognosis for pancreatic metastases of small cell lung carcinoma. In this paper we review the related literature available in English language.

Conclusions. Although pancreatic metastases are generally asymptomatic, they can rarely produce clinical symptoms or functional abnormalities. The widespread use of multi-detector computerised tomography (CT) in contemporary medical practice has led to an increased detection of pancreatic metastases in oncology patients. Tissue diagnosis is imperative because radiological techniques alone are incapable of differentiating them from primary pancreatic tumours. Pancreatic metastases occur in the relative end stage of small cell lung cancer. The main complications of these lesions, although rare, are acute pancreatitis and obstructive jaundice. Early chemotherapy can provide a survival benefit even in patients with mild acute pancreatitis or extrahepatic biliary obstruction.

Key words: lung neoplasms; carcinoma; small cell; neoplasm metastasis; pancreas

\section{Introduction}

With the improvement of imaging techniques, pancreas metastases are much more frequent than commonly appreciated. There were limited data about pancreas metastases of small cell lung cancer. Few guidelines are available on the appropriate management of such cases. The aim of this study is to review the pancreatic involvement due to small cell carcinoma of the lung.

\section{Methods}

A computerised research of literature (English language only) was performed to identify the relevant articles dealing with the subject. Using the medical subject headings and terms "pancreas metastasis or pancreatic metastases", "small cell", and "lung" we reviewed PubMed and Web of science databases be- tween 1970 and 2012. The selection criteria included patients with published demographic and clinical data regarding the treatment for cancer metastasized to pancreas. Exclusion criteria for this research included publications of patients' data in non-English language, patients without previous translation and lack of relevance of the analysis of pancreatic metastasis. Each paper was inspected and the reference lists of the selected articles were also screened systematically for additional studies of interest. More than 20 cases of primary small cell carcinoma of the pancreas were excluded. ${ }^{1-6}$ Additionally, some cases with small cell cancer in the studies were analysed just to some extent because they did not describe the detailed clinical findings ${ }^{7-18}$ Information regarding patient presentation, site of primary neoplasia, characteristics of metastasis in the pancreas, treatment, and patient demographics were summarised using descriptive statistics. All tests were performed using SPSS 15.0 for Windows. 


\section{Frequency of pancreatic metastasis}

The precise prevalence of pancreatic metastasis is not clear. The reported frequency of pancreatic metastases was $1.6 \%$ in 4955 adult autopsy cases. ${ }^{9}$ This rate was $5.9 \%$ in 1740 autopsies of another study. ${ }^{11}$ Pancreas metastasis has been observed in $25(2.1 \%)$ patients of 1172 pancreatic endoscopic ultrasoundguided fine-needle aspiration (EUS-FNA) ${ }^{19}$ This rate was, respectively $10.7 \%, 2.4 \%$, and $0.7 \%$ in different studies. ${ }^{18,20,21}$ Because the radiological examination is generally conducted in an early stage, the occurrence of pancreatic metastases in cancer patients undergoing computerised tomography (CT) should be significantly lower than in patients who have died of cancer. ${ }^{22}$ On the other hand, the metastases have been only detected at the microscopic level in $25 \%$ of the patients in autopsy series. ${ }^{9}$

The primary site of metastatic pancreatic tumour differs according to the study. The most common site can be lung carcinoma, renal cell carcinoma, colon carcinoma, or stomach carcinoma. ${ }^{9-13,15,16,18,19,21-27}$ Mesa et al. reviewed all secondary tumours of pancreas in literature by Medline between 1966 and 2003..$^{18}$ Lungs (18.7\%), gastrointestinal tract $(17.7 \%)$, kidneys $(16.3 \%)$, breasts $(10.6 \%)$, and lymphomas $(7.9 \%)$ were the most frequent secondary neoplasms in 699 cases. The reported incidence by site of origin reflects the overall incidence of cancers in the general population. However, there are a disproportionately high number of reports of metastases from renal cell carcinoma. Another review in 2004 showed that the predominant primary tumour was renal cell carcinoma in 150 cases $(45 \%)$, followed by lung carcinoma in 49 cases $(14.7 \%)$, breast carcinoma in 25 cases $(7.5 \%)$, and colon cancer in 22 cases $(6.6 \%) .{ }^{28}$ Sweeney et al. searched PubMed using the terms "pancreatic metastasis" and "cancer metastatic to the pancreas" after $2004 .{ }^{29}$ They found that the most common primary tumour site was kidney $(70.5 \%)$, followed by breast $(6.8 \%)$, lung $(5.9 \%)$, and colorectal $(5.5 \%)$ for 220 patients. It has been suggested that pancreatic metastases may arise from local lymphatic or venous dissemination because the pancreas and kidneys are located close to one another within the retroperitoneal compartment. ${ }^{25}$

Smith reviewed the incidence of metastasis to the hepatic-pancreatic-biliary axis in primary carcinoma of the lung. ${ }^{30} \mathrm{~A}$ total of $679(10 \%)$ patients were found in 6807 autopsies between 1929 and 1975. On searching medical records of 850 patients with lung cancer, $26(3.1 \%)$ cases were identified with pancreatic metastasis. ${ }^{31}$ Fluorine-18 fluorodeoxyglucose positron emission tomography (FDG-PET) is a powerful tool for oncology imaging. Pancreatic metastases were found in $1.9 \%$ of 573 cases with lung cancer by FDG-PET/CT study. ${ }^{7}$ However, only one of the pancreatic lesions had histological confirmation in this study. Because primary pancreatic cancer and pancreatitis also show FDG accumulation, the actual rate of metastasis to pancreas in lung cancer may be lower than 1.9 percent. A pathological confirmation is sometimes considered unjustifiable both from the patient's and an economic standpoint. This problem also alters the true incidence of metastatic disease of the pancreas.

The most common histological type of lung cancer that is related to pancreatic metastasis was reported as small cell lung cancer, followed by large cell carcinoma, squamous cell carcinoma, and adenocarcinoma. ${ }^{12,30,32-35}$ For metastasis-induced acute pancreatitis patients with lung cancer, the rate of small cell carcinoma to non-small cell carcinoma was 15/18 in one study and 5/15 in another study. ${ }^{8,36}$

\section{Clinical picture}

The symptoms produced by metastasis to the pancreas are variable. Most patients (50-83\%) are free of organ-specific complaints (abdominal pain, jaundice, abdominal discomfort, weight loss) when the metastasis are detected incidentally on CT during periodic clinical surveillance or follow-up. 25,37,38 Metastases can directly invade pancreatic ductal epithelium and thus may clinically mimic primary pancreatic adenocarcinoma. ${ }^{37}$ Organ-related clinical symptoms were observed in only 6 of our 18 patients. ${ }^{10}$ In a review of 220 patients, the most common presenting symptoms were jaundice $(25.2 \%)$, and abdominal pain (11.4\%). In their survey, $27.6 \%$ of the patients were asymptomatic. ${ }^{29}$ Male/female ratio was $48 / 22$ in our survey. Mean age was $59 \pm 10$ (range 37-83). The most common location was the left lung (59\%).

\section{Time of metastasis}

Pancreatic metastasis generally constitutes a late manifestation of widespread disseminated metastasis in cancer patients. ${ }^{39}$ In Mayo Clinic series, only 27 of 1357 patients (2\%) with solitary pancreatic masses had secondary pancreatic tumour. ${ }^{26}$ For small cell lung cancer, all ten patients in autopsy series and all eight patients in clinical series are 
TABLE 1. The characteristics of the patients with pancreatic metastasis-induced obstructive jaundice in small cell lung cancer

\begin{tabular}{|c|c|c|c|c|c|c|c|c|c|}
\hline References & Gender & Age & $\begin{array}{l}\text { Side of } \\
\text { primary } \\
\text { tumour }\end{array}$ & $\begin{array}{l}\text { Location of } \\
\text { secondary } \\
\text { tumour }\end{array}$ & $\begin{array}{l}\text { Pattern of } \\
\text { metastasis }\end{array}$ & $\begin{array}{l}\text { Other } \\
\text { metastases }\end{array}$ & Treatment & $\begin{array}{l}\text { Response to } \\
\text { chemotherapy }\end{array}$ & Survival \\
\hline Smith HJ.30 & NA & NA & NA & NA & NA & Present & Supportive & NA & 4 weeks \\
\hline Smith HJ.30 & NA & $\mathrm{Na}$ & NA & $\mathrm{Na}$ & NA & Present & Supportive & NA & $<2$ weeks \\
\hline Jeong $\mid B$ et al. ${ }^{34}$ & Female & 65 & Left & Head & multiple & Absent & $\begin{array}{l}\text { Percutaneous transhepatic biliary drainage following } \\
\text { chemotherapy }\end{array}$ & $\begin{array}{l}\text { Complete } \\
\text { remission }\end{array}$ & $>11$ months \\
\hline Howe HR et al. ${ }^{35}$ & Male & 53 & Right & Head & solitary & Present & Gastrojejunostomy + cholecystojejunostomy & NA & $<2$ weeks \\
\hline Obara M et al. ${ }^{40}$ & Male & 69 & Left & Head & multiple & Present & $\begin{array}{l}\text { Percutaneous transhepatic biliary drainage followed } \\
\text { chemotherapy }\end{array}$ & Partial remission & 10 months \\
\hline Kotan C et al..$^{41}$ & Male & 46 & Right & Head & solitary & Present & Pancreaticoduodenectomy followed chemotherapy & NA & 11 months \\
\hline Sakar A et al..$^{42}$ & Male & 64 & Right & Head & solitary & Absent & Gastrojejunostomy + cholecystojejunostomy & NA & $<2$ weeks \\
\hline $\begin{array}{l}\text { Dunkerley RC } \\
\text { and Dunn GD } 45\end{array}$ & Male & 72 & Left & Head & solitary & Present & Endoscopic retrograde biliary drainage, radiotherapy & NA & 6 months \\
\hline
\end{tabular}

NA = not available

presented as disseminated disease. ${ }^{9,38}$ In addition to these 18 patients, another 49 patients (Table 1, 2, and 3) also had other metastases, but 10 had solitary pancreatic metastasis. Consequently, the rate of solitary pancreatic metastasis to disseminated metastases was 10/67. The overall survival of these patients may be lower because of the extensive disease. The presence of pancreatic metastases indicates the visceral widespread and is of ominous prognostic importance. Median survival for 4 patients who had not other metastasis was 8.25 months but 1.7 months for 29 patients with extensive disease in our survey.

\section{Jaundice due to small cell lung cancer}

Lung cancer can cause biliary tract obstruction by metastasising to lymph nodes in the porta hepatis, pancreas or hepatic parenchyma. ${ }^{40}$ Johnson et al. reported that $12(9.6 \%)$ among 125 patients presented with hyperbilirubinaemia with small cell lung cancer at diagnosis. ${ }^{14}$ Five of these patients had pancreatic metastasis resulting in extrahepatic biliary obstruction, and seven had diffuse hepatic metastasis without extrahepatic biliary obstruction. When compared to extrahepatic obstruction, the resolution of jaundice is more difficult in patients with diffuse hepatic metastasis. Of 19 patients reported by Smith, eight $(66 \%)$ patients with small cell lung cancer had evidence of extrahepatic bile duct ob- struction. ${ }^{30}$ Tumours located in the head of the gland usually cause obstructive jaundice (Table 1), whereas tumours in the body and tail of the pancreas may lead to dilatation of Wirsung's duct. ${ }^{62}$ Palliative treatment by surgical biliary bypass and postoperative chemotherapy are indicated in such patients even though the patients had diffuse hepatic metastases..$^{40}$ This approach may produce extended survival exceeding 4 months. Table 1 shows that patients treated only with surgery survive several weeks. Median survival for 6 patients treated with chemotherapy was 10.5 months but 2 weeks for 5 patients treated with conservative treatment in our survey.

\section{Acute pancreatitis due to small cell lung cancer}

Associated pathological findings in cases with secondary pancreatic tumours were reported as fat necrosis $(19 \%)$, chronic pancreatitis $(11 \%)$, acute pancreatitis $(8 \%)$, and acute terminal pancreatitis $(6 \%){ }^{11}$ Although gastric cancer has been noted the most common nonpancreatic tumour associated with pancreatitis, small cell lung carcinoma has been reported to be the most common (6 of 10 patients) lung tumour causing metastasis-induced acute pancreatitis. ${ }^{46,47}$ Some lung cancer patients with metastasis-induced acute pancreatitis, especially patients with small cell lung cancer, have no 
obvious symptoms, and were easily underdiagnosed. ${ }^{36}$

In 1973, Levine and Danovitch first described a patient with small cell lung cancer in whom acute pancreatitis developed during the progression of the malignancy. ${ }^{48}$ In a series of 40 consecutive cases of small cell cancer of the lung during the period from August 1974 to August 1977, three cases of metastasis-induced acute pancreatitis were discovered. This represented an occurrence rate of 7.5 per cent. ${ }^{49}$ Although the frequency of the clinical picture was $3.3 \%$ in another series, the rate of metastasis-induced acute pancreatitis was reported as $0.12 \%$ in the largest study consisting of 802 patients. ${ }^{47,50}$

There are several mechanisms by which a metastatic tumour might induce acute pancreatitis. The first is the obstruction of the pancreatic duct by metastases or peripancreatic compression secondary to regional lymph nodes. This can lead to the activation of the pancreatic proteases, resulting in subsequent autolysis. The second is the vascular compromise by neoplastic destruction. ${ }^{10,49}$ In a series, almost $40 \%$ of patients with metastatic lesions had obstruction of the main pancreatic duct. ${ }^{22}$ More than half of these patients had neoplasms in the pancreatic head with associated biliary ductal obstruction.

In some patients, the possible causes of acute pancreatitis such as alcohol consumption, gallstone disease, or the use of antineoplastic agents such as ifosfamide, vinorelbine, and cisplatin can be found..$^{8,33,46-53}$ On the other hand, pathological investigation showed no evidence of metastatic tumour in some patients. ${ }^{52}$ This finding suggested that acute pancreatitis could be a paraneoplastic syndrome. Pancreatic metastasis could be confirmed by pancreatic biopsy, but it is often difficult to obtain a tissue diagnosis in these seriously ill patients due to high morbidity and false negative rate of biopsy. ${ }^{46}$ In our survey, thirteen patients (7 of them had post-mortem diagnosis) had tissue confirmation of pancreatic metastasis, but 13 patients had not had a pathological sampling of pancreatic tumour (Table 2). Interestingly, we found left lung predominance $(11 / 7)$ in patients with acute pancreatitis. It is necessary to investigate the lymphatic communication between the left lung and pancreas.

Treatment for tumour-induced acute pancreatitis is initially supportive. In patients with mild pancreatitis, chemotherapy may favourably influence the recovery from pancreatitis. However, chemotherapy is poorly tolerated by patients with severe pancreatitis and it is therefore inadvisable in patients with high $(>3)$ Ranson scores. ${ }^{50}$ Of the two cases reported, one patient receiving supportive treatment died in one month, and the other patient survived only seven weeks in spite of palliative abdominal radiotherapy. ${ }^{48}$ There was only one study that investigated the prognostic factors for metastasis-induced acute pancreatitis patients with lung cancer. ${ }^{36}$ Chemotherapy and performance status have been found to be significant factors for survival. In our survey median survival for 6 patients treated with chemotherapy was 6 months, but two weeks for 5 patients treated with conservative treatment.

\section{Radiographic features}

Lesions are primarily diagnosed on radiographic techniques. Imaging techniques are able to delineate the mass and evaluate its size and lymph node status, as well as the extent of vascular invasion. Pancreatic metastasis must be distinguished from local invasion of malignant gastrointestinal tumours. Although abdominal ultrasound is the first-line imaging, CT is the most frequently used method for studying pancreatic cancer. ${ }^{67}$ Ultrasonography also helps to distinguish the aetiology of the common causes of pancreatitis and it is important to exclude cholelithiasis if chemotherapy is to be considered. ${ }^{54}$

The sensitivity of abdominal ultrasound in the detection of all tumours in the pancreas was found as $89 \%$ in a prospective study. ${ }^{68}$ The sonographic appearance of metastasis appeared as homogenous, well-demarcated solid lesion with a more hypoechoic internal structure than the pancreatic parenchyma. The pancreatic duct is usually not dilated. Although metastases can be hypovascular or hypervascular depending on the primary malignancy, a pancreatic mass rich in blood flow, as indicated by colour Doppler ultrasound, is more likely to be a metastasis than a primary pancreatic carcinoma. ${ }^{39,69,70}$ The metastatic lesion from a renal cell carcinoma is usually highly vascular, and contrast-enhanced ultrasound or angiography is very useful for diagnosis. ${ }^{12}$ Endoscopic ultrasound can show invisible metastases in abdominal ultrasound. ${ }^{55}$ Interestingly, abdominal ultrasound can show invisible metastases in CT. ${ }^{56}$ Endoscopic ultrasound features of primary pancreatic cancer and metastatic lesion were similar with respect to tumour size, echogenicity, or consistency. Although endoscopic ultrasound is probably superior for de- 
TABLE 2. The characteristics of the patients with metastasis-induced acute pancreatitis in small cell lung cancer

\begin{tabular}{|c|c|c|c|c|c|c|c|c|c|c|}
\hline References & Gender & Age & $\begin{array}{l}\text { Side of } \\
\text { primary } \\
\text { tumor }\end{array}$ & $\begin{array}{l}\text { Location of } \\
\text { secondary } \\
\text { tumor }\end{array}$ & $\begin{array}{l}\text { Pattern of } \\
\text { metastasis }\end{array}$ & $\begin{array}{l}\text { Tissue } \\
\text { diagnosis }\end{array}$ & $\begin{array}{l}\text { Other } \\
\text { metastases }\end{array}$ & Treatment & $\begin{array}{l}\text { Response to } \\
\text { chemotherapy }\end{array}$ & Survival \\
\hline Woo JS et al..$^{33}$ & Female & 45 & Left & Head & multiple & No & Yes & Endoscopic stenting & NA & NA \\
\hline Liu SF et al. ${ }^{36}$ & Male & 44 & NA & NA & NA & Yes & Yes & Chemotherapy & NA & 7.6 months \\
\hline Liu SF et al. ${ }^{36}$ & Female & 44 & NA & NA & NA & Yes & Yes & Chemotherapy & NA & 3.2 months \\
\hline Liu SF et al. ${ }^{36}$ & Male & 51 & NA & NA & NA & Yes & Yes & Chemotherapy & NA & 9 months \\
\hline Liu SF et al. ${ }^{36}$ & Male & 75 & NA & NA & NA & Yes & Yes & Chemotherapy & NA & 1 month \\
\hline Liu SF et al. ${ }^{36}$ & Female & 68 & NA & NA & NA & Yes & Yes & Conservative & NA & 2.7 months \\
\hline Kim KH et al. ${ }^{46}$ & Male & 63 & Right & NA & multiple & No & Yes & Conservative & NA & NA \\
\hline Chowhan NM et al. ${ }^{47}$ & Male & 55 & Left & Tail & NA & No & Yes & Conservative & NA & 2 weeks \\
\hline Chowhan NM et al. ${ }^{47}$ & Male & 48 & Right & Head & Solitary & No & Yes & Conservative & NA & 2 weeks \\
\hline Levine M et al. ${ }^{48}$ & Male & 45 & Right & All & NA & Autopsy & Yes & Conservative & NA & 1 month \\
\hline Yeung KY et al. ${ }^{49}$ & Male & 53 & Left & Head and body & Diffuse enlargement & Autopsy & Yes & Chemotherapy & Partial remission & 5.5 months \\
\hline Yeung KY et al. ${ }^{49}$ & Male & 53 & Right & NA & NA & Autopsy & Yes & Chemotherapy & Partial remission & 5.5 months \\
\hline Yeung KY et al. ${ }^{49}$ & Female & 37 & Right & NA & Diffuse enlargement & No & No & Chemotherapy & Complete remission & 3.5 months \\
\hline Stewart KC et al..$^{50}$ & Female & 44 & Left & Head & Solitary & No & Yes & Chemotherapy & Partial remission & $>6$ months \\
\hline Papagiannis A et al. ${ }^{51}$ & Male & 52 & Left & NA & Diffuse enlargement & No & $?$ & Conservative & NA & 3 weeks \\
\hline Allan SG et al. ${ }^{52}$ & Female & 73 & Left & NA & Diffuse enlargement & No & Yes & Conservative & NA & 5 days \\
\hline Allan SG et al..$^{52}$ & Male & 67 & NA & NA & Diffuse enlargement & No malignity & Yes & Conservative & NA & 10 days \\
\hline Huang YW et al. ${ }^{53}$ & Female & 68 & Left & NA & Diffuse enlargement & No & Yes & Conservative & NA & 9 days \\
\hline Hall M et al..$^{54}$ & Male & 67 & Left & Head & NA & Autopsy & Yes & Conservative & NA & 2 weeks \\
\hline Wurm Johansson G et al. ${ }^{55}$ & Female & 52 & NA & Head and body & multiple & EUS-FNA & NA & $\begin{array}{l}\text { Biliary stent + } \\
\text { chemotherapy }\end{array}$ & NA & NA \\
\hline Tanaka H et al. ${ }^{56}$ & Female & 51 & Left & Body and tail & multiple & No & Yes & Chemotherapy & Complete remission & 8 months \\
\hline Noseda A et al. ${ }^{57}$ & Male & 58 & Left & Head & Solitary & No & Yes & Conservative & NA & 7 weeks \\
\hline Schmitt JK58 & Male & 58 & Left & NA & NA & Autopsy & Yes & Chemotherapy & NA & 6.5 weeks \\
\hline Evans $A^{T 5}$ & Female & 45 & Right & NA & Diffuse enlargement & Autopsy & Yes & Conservative & NA & 8 days \\
\hline Chao WC et al. ${ }^{60}$ & Female & 65 & Left & NA & multiple & No & Yes & Conservative & NA & 20 days \\
\hline Maclennan AC et al..$^{61}$ & Female & 56 & Right & All & multiple & Autopsy & $?$ & Conservative & NA & 5 weeks \\
\hline
\end{tabular}

NA = not available; EUS-FNA = ultrasound-guided fine-needle aspiration

tection of small tumours, helical CT appears equal to or perhaps even better than endoscopic ultrasound for staging pancreatic neoplasms..$^{20}$

For 12 patients with pancreas metastasis, abdominal ultrasonography had reported hypoechoic lesion in 6 patients, a hypertrophic aspect involving the head of the pancreas with dilatation of the main pancreatic duct in one patient, and an aspect suggestive of acute pancreatitis in one patient. ${ }^{15}$ In their study, abdominal CT was performed in 19 patients and revealed tumours in 13 patients, increased pancreatic volume in 5 patients, and an aspect compatible with pancreatitis in one patient. CT technology has improved greatly over the last decade. For primary pancreatic cancer, an accuracy of $99 \%$ has been reported for prediction of vascular invasion by tumour with multi-detector helical CT (MDCT). ${ }^{71}$ Although the sensitivity of modern MDCT scanners in demonstrating pancreatic metastasis is still not known, MDCT with 2D multiplanar reconstructions (MPR) and three-dimensional rendering allows detection of lesions that are not visible on routine CT images. ${ }^{53}$ In a study of 11 cases, nearly $30 \%$ of pancreatic metastases were missed on routine transaxial images and detected only on thin slice or MPR images. ${ }^{7}$ There was only one study that investigated the diagnostic performance of MDCT in pancreatic metastases. ${ }^{67}$ All metastatic lesions in 17 patients, ranged between 8 and $40 \mathrm{~mm}$, were demonstrated by MDCT. 
Precontrast CT images of the pancreas show either isodense or hypodense lesions when compared to the normal parenchyma, with rare regions of calcification. ${ }^{69}$ Solitary metastases typically demonstrate areas of low attenuation (probably indicative for necrotic foci) on contrast enhanced $\mathrm{CT}$, while the diffuse form of metastasis remains isodense following intravenous contrast medium. ${ }^{10,41}$ A peripheral rim of enhancement after intravenous contrast medium is usually demonstrated. Rim enhancement is especially common in lesions larger than $1.5 \mathrm{~cm}$ in size, whereas smaller tumours display a more uniform vascular pattern. ${ }^{41}$ Although some authors did not observe a correlation between tumour size and pattern of enhancement, they also found a peripheral enhancement in $73 \%$ of the patients. ${ }^{24}$ The peripheral enhancement of tumour tissue observed in many cases reflects a degree of vascular perfusion that is not typical of primary pancreatic adenocarcinoma, whereas ductal adenocarcinoma of the pancreas typically appears as a uniformly nonenhancing mass at contrast-enhanced. ${ }^{22,24}$

CT can occasionally fail to show subtle differences in attenuation between normal pancreatic tissue and non-necrotic or non-cystic neoplastic tissue. ${ }^{23}$ Of 34 patients with autopsy-proven secondary tumour, pancreatic abnormalities were documented on non-helical abdominal CT only in $18(53.8 \%)$ cases. Initial CT of the pancreas can be normal in appearance in patients with metastasis. ${ }^{10}$ Lymphatic metastasis of the pancreas can occur without any tumour formation, what is often seen in stomach carcinoma. ${ }^{11}$

On magnetic resonance imaging, pancreatic metastases typically appear hypointense and well circumscribed compared with normal gland tissue on unenhanced T1-weighted images, both with and without fat saturation. Following intravenous gadopentetate dimeglumine administration, a rim of enhancement is usually visible in larger lesions and homogenous enhancement is typically demonstrated in smaller tumours. On T2-weighted images, the lesions are slightly heterogeneous and moderately hyperintense. Hypointense nodules are sometimes visible on T2-weighted images, especially in the diffusely enlarged type. ${ }^{38,41}$

A definitive diagnosis requires a pathologic examination of a biopsy or surgical specimen. Endoscopic ultrasound-guided fine-needle aspiration has become the preferred method for cytologic-tissue acquisition of pancreatic masses, especially following equivocal CT imaging. ${ }^{69}$ Nevertheless, the histological distinction between primary pan- creatic cancer and metastatic tumour is sometimes difficult to establish. ${ }^{15}$

\section{Radiological pattern of metastasis}

The majority of overall metastatic lesions were found in the head of the pancreas. ${ }^{16,20,29,32}$ For lung cancer, some authors reported that the majority of metastatic lesions were observed in the body or the head of the pancreas. ${ }^{33,38}$ However, our review showed that the most common macroscopic location is the head $(76 \%)$ of the gland for small cell lung cancer (Table 1, Table 2, and Table 3). The body was the second most common site (15\%) for solitary involvements.

Three patterns of metastatic involvement of the pancreas have been described. The first and most common, reported in $50-80 \%$ of cases, is that of a single localised mass. ${ }^{19} \mathrm{~A}$ second pattern of diffuse pancreatic enlargement has been reported in 15$44 \%$ of cases. Diffuse enlargement is characterised by a diffuse infiltration of malignant cells along the interlobular septa, which causes the destruction of large parts of the pancreatic lobules..$^{23}$ The gland has homogenous density in CT appearance. The third pattern is multiple pancreatic nodules (10$44 \%)$, represented by many small nodules which can coalesce occasionally into larger masses. ${ }^{12,22,23,37}$ The attenuation of the neoplastic nodules may be variable. ${ }^{49}$

Solitary nodule was the usual pattern of pancreatic metastasis, both for overall tumours and for lung cancer. ${ }^{16,22-25,31}$ Although the most common cause of diffuse infiltrative type of metastasis reported is small cell carcinoma of the lung [10], in our survey of 50 patients with small cell lung cancer, we observed a solitary nodule in 29 patients $(57 \%)$, multiple nodules in 14 patients $(27 \%)$, and diffuse enlargement in $8(16 \%)$ the patients. Radiological pattern can be related to the invasiveness of metastatic carcinoma. ${ }^{10}$ Interestingly, we found that diffuse enlargement is the most common pattern $(50 \%)$ in patients with acute pancreatitis (Table 2). On the other hand, the most common type of metastasis was diffuse involvement in histological examination. ${ }^{10}$

\section{Conclusions}

The frequency of pancreatic metastasis varies between $1.6 \%$ and $10.6 \%$ in autopsy studies. 
TABLE 3. Pattern of metastasis in small cell lung cancer

\begin{tabular}{|c|c|c|c|c|c|}
\hline References & Gender & Age & Location & Type & Other metastases \\
\hline Sato Met al.? & male & 78 & body & solitary & Yes \\
\hline Sato Met al.? & male & 58 & NA & NA & Yes \\
\hline Sato Met al.? & male & 75 & NA & NA & Yes \\
\hline Muranaka T et al. ${ }^{10}$ & male & 60 & NA & Diffuse enlargement & NA \\
\hline Volmar KE et al. ${ }^{16}$ & male & 58 & NA & NA & No \\
\hline Volmar KE et al. ${ }^{16}$ & male & 65 & NA & NA & No \\
\hline Mesa H et al..$^{18}$ & NA & NA & body & NA & NA \\
\hline Gilbert CM et al. ${ }^{19}$ & male & 65 & head & multiple & NA \\
\hline Gilbert CM et al. ${ }^{19}$ & male & 58 & head & solitary & NA \\
\hline Gilbert CM et al. ${ }^{19}$ & female & 58 & body & solitary & NA \\
\hline Layfield LJ et al. ${ }^{21}$ & female & 57 & head & NA & NA \\
\hline Tsitouridis I et al. ${ }^{24}$ & male & 69 & Head, body, tail & multiple & Yes \\
\hline Tsitouridis I et al. ${ }^{24}$ & male & 59 & Head and tail & multiple & yes \\
\hline DeWitt J et al.32 & female & 49 & head & solitary & Yes \\
\hline DeWitt J et al.32 & female & 75 & head & solitary & Yes \\
\hline DeWitt J et al.32 & male & 49 & head & solitary & NA \\
\hline DeWitt J et al.32 & male & 65 & head & solitary & NA \\
\hline Scatarige JC et al..$^{37}$ & male & 48 & head & solitary & Yes \\
\hline Scatarige JC et al.37 & female & 68 & Head and body & multiple & NA \\
\hline Xi-wen S et al. ${ }^{38}$ & male & 74 & body & solitary & Yes \\
\hline Xi-wen S et al. ${ }^{38}$ & male & 50 & NA & solitary & Yes \\
\hline Xi-wen S et al. ${ }^{38}$ & male & 68 & NA & solitary & Yes \\
\hline Xi-wen S et al. ${ }^{38}$ & male & 52 & NA & solitary & Yes \\
\hline Xi-wen S et al. ${ }^{38}$ & female & 39 & NA & solitary & Yes \\
\hline Xi-wen $S$ et al. ${ }^{38}$ & male & 53 & NA & solitary & Yes \\
\hline Xi-wen S et al. ${ }^{38}$ & male & 53 & NA & multiple & Yes \\
\hline Xi-wen S et al. ${ }^{38}$ & male & 76 & NA & solitary & yes \\
\hline Katsuura Y et al. ${ }^{39}$ & male & 83 & body & solitary & Yes \\
\hline Merkle EM et al. ${ }^{62}$ & male & 55 & tail & solitary & NA \\
\hline Das DK et al. ${ }^{63}$ & male & 66 & tail & solitary & NA \\
\hline Walshe T et al. ${ }^{64}$ & female & 60 & neck & solitary & No \\
\hline Boo SJ et al..$^{65}$ & male & 44 & head & NA & No \\
\hline Boo SJ et al. ${ }^{65}$ & male & 75 & head & NA & No \\
\hline Boo SJ et al. ${ }^{65}$ & male & 61 & head & NA & Yes \\
\hline Ottaiano A et al. .6 & male & 65 & Head, body, tail & NA & No \\
\hline
\end{tabular}

NA = not available

Secondary tumours constitute $3-17 \%$ of all pancreatic tumours in clinical studies, but $43-65 \%$ in autopsy studies. The most common pattern for small cell lung cancer is a single localised mass in the head of the gland. The primary tumour is generally found in the left lung. Less than $15 \%$ of the patients had solitary pancreatic metastasis but other extensive disease. In spite of the advent of other imaging modalities, CT is still the gold standard for the evaluation of pancreatic pathology. In the patients 
with jaundice, systemic chemotherapy might resolve the obstruction with symptomatic relief for the patient. Metastasis-induced acute pancreatitis can be a lethal event, and the diagnosis should be considered in any patient with known small cell carcinoma in whom an acute abdomen develops. Because of the aggressive nature of the tumour, all patients who had an appropriate performance status should receive systemic chemotherapy. The prognosis is better in patients with solitary pancreatic metastasis.

\section{References}

1. Wang $D$, Rong $Y, W u, W$, Jin $D$. Primary small cell carcinoma of the pancreas: rare type of pancreatic cancer and review of the literatures. World J Surg Oncol 2012; 10: 32

2. Sakamoto H, Kitano M, Komaki T, Noda K, Chikugo T, Kudo M. Small cell carcinoma of the pancreas: role of EUS-FNA and subsequent effective chemotherapy using carboplatin and etoposide. J Gastroenterol 2009; 44: 432-8.

3. Iwasa S, Morizane C, Okusaka T, Ueno H, Ikeda M, Kondo S, et al. Cisplatin and etoposide as first-line chemotherapy for poorly differentiated neuroendocrine carcinoma of the hepatobiliary tract and pancreas. Jpn J Clin Oncol 2010; 40: 313-8.

4. Winter JM, Narang AK, Mansfield AS, Herman JM, Cameron JL, Laheru D et al. Resectable pancreatic small cell carcinoma. Rare Tumors 2011; 3: e5.

5. Chung MS, Ha TK, Lee KG, Paik SS. A case of long survival in poorly differentiated small cell carcinoma of the pancreas. World J Gastroenterol 2008 14: 4964-7.

6. Fitzmaurice C, Cornett DD, Spier BJ, Pfau P. Metastatic pancreatic small-cell carcinoma presenting as acute pancreatitis. J Clin Oncol 2010; 28: e748e749.

7. Sato M, Okumura T, Kaito K, Kiyoshima M, Asato $Y$, Uchiumi K, et al. Usefulness of FDG-PET/CT in the detection of pancreatic metastases from lung cancer. Ann Nucl Med 2009; 23: 49-57.

8. Lin JT, Chen PM, Wang WS. Metastasis-induced acute pancreatitis in lung cancer. Adv Ther 2005; 22: 225-33.

9. Adsay NV, Andea A, Basturk O, Kilinc N, Nassar H, Cheng JD. Secondary tumors of the pancreas: an analysis of a surgical and autopsy database and review of the literature. Virchows Arch 2004; 444: 527-35.

10. Muranaka T, Teshima K, Honda H, Nanjo T, Hanada K, Oshiumi Y. Computed tomography and histologic appearance of pancreatic metastases from distant source Acta Radiol 1989; 30: 615-9.

11. Nakamura E, Shimizu M, Itoh T, Manabe T. Secondary tumors of the pancreas: clinicopathological study of 103 autopsy cases of Japanese patients. Pathol Int 2001; 51: 686-90.

12. Sato $M$, Ishida $H$, Konno $K$, Hamashima $Y$, Naganuma $H$, Komatsuda $T$, et al. Pancreatic metastasis: sonographic findings. Abdom Imaging 2001; 26 $72-5$

13. Matsukuma S, Suda K, Abe H, Ogata S, Wada R. Metastatic cancer involving pancreatic duct epithelium and its mimicry of primary pancreatic cancer. Histopathology 1997; 30: 208-13.

14. Johnson DH, Hainsworth JD, Greco FA. Extrahepatic biliary obstruction caused by small-cell lung cancer. Ann Intern Med 1985; 102: 487-90.

15. Moussa A, Mitry E, Hammel P, Sauvanet A, Nassif T, Palazzo L, et al Pancreatic metastases: a multicentric study of 22 patients. Gastroentero Clin Biol 2004; 28: 872-6.

16. Volmar KE, Jones $\mathrm{CK}$, Xie HB. Metastases in the pancreas from nonhematologic neoplasms: Report of 20 cases evaluated by fine-needle aspiration. Diagn Cytopathol 2004; 31: 216-20.
17. Yoon WJ, Ryu JK, Kim YT, Yoon YB, Kim SW, Kim WH. Clinical features of metastatic tumors of the pancreas in Korea: A single-center study. Gut Liver 2011; 5: 61-4.

18. Mesa H, Stelow EB, Stanley MW, Mallery SM, Lai R, Bardales RH. Diagnosis of nonprimary pancreatic neoplasms by endoscopic ultrasound-guided fineneedle aspiration. Diagn Cytopathol 2004; 31: 313-8.

19. Gilbert CM, Monaco SE, Cooper ST, Khalbuss WE. Endoscopic ultrasoundguided fine-needle aspiration of metastases to the pancreas: A study of 25 cases. Cytojournal 2011; 8: 7 .

20. Fritscher-Ravens A, Sriram PV, Krause C, Atay Z, Jaeckle S, Thonke F, et al. Detection of pancreatic metastases by EUS-guided fine-needle aspiration. Gastrointest Endosc 2001; 53: 65-70.

21. Layfield $\sqcup$, Hirschowitz SL, Adler DG. Metastatic disease to the pancreas documented by endoscopic ultrasound guided fine-needle aspiration: A seven year experience. Diagn Cytopathol 2012; 40: 228-33.

22. Klein KA, Stephens DH, Welch TJ. CT characteristics of metastatic disease of the pancreas. Radiographics 1998; 18: 369-78.

23. Cubilla AL, Fitzgerald PJ. Cancer (non-endocrine) of the pancreas: A suggested classification. Monogr Pathol 1980; 21: 82-110.

24. Tsitouridis I, Diamantopoulou A, Michaelides M, Arvanity M, Papaioannou S. Pancreatic metastases: CT and MRI findings. Diagn Interv Radiol 2010; 16: 45-51.

25. Hung JH, Wang SE, Shyr YM, Su CH, Chen $\mathrm{TH}$, Wu CW. Resection for secondary malignancy of the pancreas. Pancreas 2012; 41: 121-9.

26. Roland CF, van Heerden JA. Nonpancreatic primary tumours with metastasis to the pancreas. Surg Gynecol Obstet 1989; 168: 345-7.

27. Sperti C, Pasquali C, Liessi G, Pinciroli L, Decet G, Pedrazzoli S. Pancreatic resection for metastatic tumors to the pancreas. J Surg Oncol 2003; 83: 161-6.

28. Minni F, Casadei R, Perenze B, Greco VM, Marrano N, Margiotta A, et al. Pancreatic metastases: observations of three cases and review of the literature. Pancreatology 2004; 4: 509-20.

29. Sweeney AD, Wu MF, Hilsenbeck SG, Brunicardi FC, Fisher WE. Value of pancreatic resection for cancer metastatic to the pancreas. J Surg Res 2009; 156: $189-98$

30. Smith HJ. Extrahepatic bile duct obstruction in primary carcinoma of the lung: incidence, diagnosis, and non-operative treatment. J Natl Med Assoc 1980; 72: 215-20.

31. Maeno $\mathrm{T}$, Satoh $\mathrm{H}$, Ishikawa $\mathrm{H}$, Yamashita $\mathrm{YT}$, Naito T, Fujiwara M, et al. Patterns of pancreatic metastasis from lung cancer. Anticancer Res 1998; 18: $2881-4$

32. DeWitt J, Jowell P, Leblanc J, McHenry L, McGreevy K, Cramer H, et al. EUS-guided FNA of pancreatic metastases: a multicenter experience. Gastrointest Endosc 2005; 61: 689-96.

33. Woo JS, Joo KR, Woo YS, Jang JY, Chang YW, Lee J 2nd, et al. Pancreatitis from metastatic small cell lung cancer successful treatment with endoscopic intrapancreatic stenting. Korean J Intern Med 2006; 21: 256-61.

34. Jeong IB, Kim SM, Lee TH, Im EH, Huh KC, Kang YW, et al. Pancreatic metastasis and obstructive jaundice in small cell lung carcinoma. Korean J Intern Med 2006; 21: 132-5.

35. Howe HR, Hansen KJ, Albertson DA. Metastatic oat cell carcinoma of the lung producing extrahepatic bile duct obstruction. South Med J 1985; 78: $1398-9$.

36. Liu SF, Zhang S, Chen YC, Fang WF, Lin MC, Su MC, et al. Experience of cancer care for metastasis-induced acute pancreatitis patients with lung cancer. $J$ Thorac Oncol 2009; 4: 1231-5.

37. Scatarige JC, Horton KM, Sheth S, Fishman EK. Pancreatic parenchymal metastases: Observations on helical CT. AJR Am J Roentgenol 2001; 176: 695-9.

38. Xi-wen S, Shu-zhen C. Characterization of pancreatic metastases from primary lung cancer using magnetic resonance imaging. Clin Imaging 2010 34: 351-4.

39. Katsuura $\mathrm{Y}$, Ishida $\mathrm{H}$, Komatsuda T, Kurokawa H. Pancreatic metastasis from lung cancer. J Med Ultrasonics 2006; 33:253-4.

40. Obara M, Satoh H, Yamashita YT, Kamma H, Ohtsuka M, Hasegawa S, et al. Metastatic small cell lung cancer causing biliary obstruction. Med Oncol 1998; 15:292-4. 
41. Kotan C, Er M, Ozbay B, Uzun K, Barut I, Ozgoren E. Extrahepatic biliary obstruction caused by small-cell lung cancer: a case report. Acta Chir Belg 2001; 101: 190-2.

42. Sakar A, Kara E, Aydede H, Ayhan S, Celik P, Yorgancioglu A. A case of small cell lung carcinoma presenting with jaundice due to pancreatic metastasis. Tuberk Toraks 2005; 53: 181-4.

43. Singh D, Vaidya OU, Sadeddin E, Yousef O. Role of endoscopic ultrasound and endoscopic retrograde cholangiopancreatography in isolated pancreatic metastasis from lung cancer. World J Gastrointest Endosc 2012; 4: 328-30.

44. Ochi N, Takigawa N, Yasugi M, Ishida E, Kawamoto H, Taniguchi A, et al. Obstructive jaundice at the initial presentation in small-cell lung cancer. Int Med Case Reports J 2010; 3: 9-12

45. Dunkerley RC, Dunn GD. Use of retrograde cholangiography in guiding radiotherapy of obstructive jaundice due to tumor. Am J Gastroenterol 1976; 66: 283-6.

46. Kim KH, Kim CD, Lee SJ, Lee G, Jeen YT, Lee HS, et al. Metastasis-induced acute pancreatitis $\mathrm{n}$ a patient with small cell carcinoma of the lung. J Korean Med Sci 1999; 14: 107-9.

47. Chowhan NM, Madajewicz S. Management of metastases-induced acute pancreatitis in small cell carcinoma of the lung. Cancer 1990; 65: 1445-8.

48. Levine $M$, Danovitch $S$. Metastatic carcinoma to the pancreas: Another cause for acute pancreatitis. Am J Gastroenterol 1973; 60: 290-4.

49. Yeung KY, Haidak DJ, Brown JA, Anderson D. Metastasis-induced acute pancreatitis in small cell bronchogenic carcinoma. Arch Intern Med 1979; 139: 552-4.

50. Stewart KC, Dickout WJ, Urschel JD. Metastasis-induced acute pancreatitis as the initial manifestation of bronchogenic carcinoma. Chest 1993; 104 98-100.

51. Papagiannis A, Zarogoulidis K, Delis D, Patakas D. A 52-year-old man with lung mass and acute abdominal pain. Chest 2000; 117: 894-6.

52. Allan SG, Bundred N, Eremin O, Leonard RCF. Acute pancreatitis in as sociation with small cell lung carcinoma: potential pitfall in diagnosis and management. Postgrad Med 1985; 61: 643-4.

53. Huang YW, Yang JC, Chang YL, Tsang YM, Wang TH. Acute pancreatitis combined with acute Budd-Chiari syndrome as the initial manifestation of smal cell lung cancer. J Formos Med Assoc 2005; 104: 431-5.

54. Hall M, Bundred NJ, Hall AW. Oat cell carcinoma of the bronchus and acute pancreatitis. Eur J Surg Oncol 1987; 13: 371-2.

55. Wurm Johansson G, Toth E, Torp J, Ehinger A, Andersson L, Thorlacius H. Acute pancreatitis evoked by small-cell lung carcinoma metastases and detected by endoscopic ultrasound. Endoscopy 2012; 44: E45-E46.

56. Tanaka H, Nakazawa T, Yoshida M, Miyabe K, Okumura F, Naitoh I, et al. Metastasis-induced acute pancreatitis in a patient with small cell carcinoma of the lungs. J Pancreas 2009; 10: 557-61.

57. Noseda A, Gangii D, Cremer M. Acute pancreatitis as presenting symptom and sole manifestation of small cell lung carcinoma. Dig Dis Sci 1987; 32: 327-31.

58. Schmitt JK. Pancreatitis and diabetes mellitus with metastatic pulmonary oat-cell carcinoma. Ann Intern Med 1985; 103: 638-9.

59. Evans AT. Necrotising pancreatitis and diabetes associated with disseminated small cell carcinoma of the lung. Scott Med J 1988; 33: 377

60. Chao WC, Wang SY, Lin CY, Wang TE, Peng MJ. Metastatic small-cell lun cancer presenting as acute pancreatitis. J Cancer Res Pract 2010; 26: 270-4.

61. Maclennan AC, Macleod IA. Case report: small cell carcinoma induced acute pancreatitis. Br J Radiol 1993; 66: 161-2.

62. Merkle EM, Boaz T, Kolokythas O, Haaga JR, Lewin JS, Brambs HJ. Metastases to the pancreas. BrJ Radiol 1998; 71: 1208-14.

63. Das DK, Muqim AT, Haji BI, Al-Bishi K, Abdulghani R. Pancreatic metastasis in a case of small cell lung carcinoma: Diagnostic role of fine-needle aspiration cytology and immunocytochemistry. J Cytol 2011; 28: 226-8.

64. Walshe T, Martin ST, Khan MF, Egan A, Ryan RS, Tobbia I, et al. Isolated pancreatic metastases from a bronchogenic small cell carcinoma. Ir Med 2009; 102: 119-20.
65. Boo SJ, Kim MH, Kim YS, Ryu CH, Kim HJ, Park do H, et al. [Clinical characteristics of pancreatic metastases.] [Korean] Korean J Gastroenterol 2011 57: 358-64.

66. Ottaiano A, Barletta E, Maione P, Fiore F, Pisano C, Di Maio M, et al Pancreatic involvement from heavily pretreated small cell lung cancer successfully treated with transcatheter intra-arterial chemotherapy: a case report with local and systemic disease control. Tumori 2002; 88: 535-7.

67. Angelelli G, Mancini M, Pignataro P, Pedote P, Scardapane A. Multidetector computed tomography in the study of pancreatic metastases. Radiol Med 2012; 117: 369-77.

68. Karlson BM, Ekbom A, Lindgren PG, Kallskog V, Rastad J. Abdominal US for diagnosis of pancreatic tumor: Prospective cohort analysis. Radiology 1999; 213: $107-11$.

69. Ahmed S, Johnson PT, Hruban R, Fishman EK. Metastatic disease to the pancreas: pathologic spectrum and CT patterns. Abdom Imaging 2012; 37: 21-8.

70. Wernecke K, Peters PE, Galanski M. Pancreatic metastases: US evaluation. Radiology 1986; 160: 399-402.

71. Tunaci M. Multidetector row CT of the pancreas. Eur J Radiol 2004; 52: 18-30. 